\title{
Evaluation of spot urinary albumin - creatinine ratio as a screening tool in the prediction of pre-eclampsia in early pregnancy: a pilot study
}

\author{
Rajeshwari G.*, Akshaya Girish Dongare, G. L. Patil, Tejaswi Pujar
}

Department of Obstetrics and Gynecology, S. S. Institute of Medical Sciences and Research Centre Davangere, Karnataka, India

Received: 18 October 2019

Revised: 04 December 2019

Accepted: 12 December 2019

\section{*Correspondence:}

Dr. Rajeshwari G.,

E-mail: dr.raj.obg@gmail.com

Copyright: () the author(s), publisher and licensee Medip Academy. This is an open-access article distributed under the terms of the Creative Commons Attribution Non-Commercial License, which permits unrestricted non-commercial use, distribution, and reproduction in any medium, provided the original work is properly cited.

\section{ABSTRACT}

Background: Pre-eclampsia is one of the leading causes of maternal and perinatal morbidity and mortality in India. Objective of this study was to establish whether a spot urinary albumin/creatinine ratio (ACR) measured between 1828 weeks of gestation can predict subsequent pre-eclampsia in asymptomatic pregnant women.

Methods: A prospective observational study involving 50 registered antenatal cases visiting the obstetrics outpatient department between 18-28 weeks of singleton pregnancy with nil proteinuria upon dipstick measurement were included. ACR was determined from random single midstream urine sample. Statistical analysis was performed using Chi square test and Student's t-test.

Results: Of the study group, 10 patients had high ACR value, with 8(80\%) developed pre-eclampsia and 2(20\%) remained normotensive. ACR had a sensitivity of $80 \%$, specificity $97.56 \%$, positive predictive value of $88.89 \%$, diagnostic accuracy of the test being $94.12 \%$.

Conclusions: The spot urinary protein creatinine ratio is a reliable predictor for pre-eclampsia in pregnancy.

Keywords: Preeclampsia predictors, Pregnancy hypertension, Spot urinary protein test

\section{INTRODUCTION}

Pre-eclampsia is one of the leading causes of maternal and perinatal morbidity and mortality in India. It complicates $5-8 \%$ of all pregnancies, more common among primigravidas $(14.1 \%)$ as compared to multigravidas $(5.7 \%) .{ }^{1-3}$

According to the American college of obstetrics and gynaecology (ACOG) criteria, pre-eclampsia is diagnosed when the blood pressure is higher than 140/90 $\mathrm{mmHg}$ and proteinuria more than $300 \mathrm{mg} / 24$ hour, observed on at least two occasions more than 6 hours apart after the $20^{\text {th }}$ week of pregnancy. ${ }^{4}$ However if the blood pressure was higher than $160 / 100 \mathrm{mmHg}$ and proteinuria more than $500 \mathrm{mg} / 24$ hour with imminent symptoms, it will termed as severe pre-eclampsia. ${ }^{5}$

Pre-eclampsia is a multisystem disorder. The pathophysiological mechanism is characterized by a failure of the trophoblastic invasion of the spiral arterioles, which may be associated with an increased vascular resistance of the uterine artery and a decreased perfusion of the placenta.

Abnormal deposition of proteinaceous like material at the glomerular basement membrane will lead to glomeruloendotheliosis and in severe cases leads to renal impairment and failure. Ongoing renal dysfunction in pre-eclampsia will result in proteinuria, which is one of 
the diagnostic criteria of its severity. Microalbuminuria which is a hallmark of endothelial dysfunction precedes proteinuria. Detection of microalbuminuria is used as a predictive test for preeclampsia.

Microalbuminuria is currently defined as a urinary albumin excretion (UAE) of $30-300 \mathrm{mg} / 24$ hours, if measured in a 24 -hour urine collection or $30-300 \mathrm{mg} / \mathrm{g}$ if measured with the use of the urinary albumin: creatinine ratio (UACR) in a spot urine collection.

Cornerstones of antenatal care includes a screening programme directed at the detection of pre-eclampsia with regular blood pressure measurements and urinalysis for proteinuria. The "dipstick analysis" using visual reagent strips is quick, portable and easy to do however it has relatively low sensitivity and specificity with high false positive and false negative rates, so it is almost always followed by gold standard test that is 24 hour urine collection. ${ }^{6-8}$ But it is cumbersome, time consuming, inconvenient and subject to errors such as incomplete collection leading to inaccuracies (in 13$68 \%) .{ }^{9}$ So, there is a need for a rapid as well as a valid, accurate test to identify significant urinary proteinuria.

Evidence from previous studies shows a strong association between spot albumin to creatinine ratio and 24-hour protein excretion.

The International society for the study of hypertension in pregnancy has accepted spot urinary albumin to creatinine ratio as a method for identification of significant proteinuria. The National kidney foundation guidelines have suggested that the urine albumin: creatinine ratio should be used to detect and monitor proteinuria. $^{10}$

Also, the Australian society for the study of hypertension in pregnancy and the International society for the study of hypertension in pregnancy have proposed use of urine albumin creatinine ratio as an alternative to 24-hour urine collection. $^{11}$

\section{Spot urine albumin}

Creatinine ratio is a simple test with potential benefits as women prone to develop pre-eclampsia in later part of the pregnancy can be detected at an early stage, which could help in early monitoring for symptoms and signs of preeclampsia in the pregnant lady and in the early identification of intrauterine growth restriction in the fetus. There is some evidence to support the prophylactic benefit of the early introduction of aspirin, calcium and heparin in such high-risk pregnant women.

Early detection of proteinuria in pregnancy is a predictive test for pre-eclampsia in pregnancy. With a view to prevent untoward complications a simple spot urine test for albumin can prevent potential complications to the mother and the baby.

\section{METHODS}

\section{Data collection}

After approval from the institutional ethical committee with reference number IERB/O.No.156/2018 and a written informed consent from the patients during the study period of one year fulfilling inclusion criteria.

A prospective observational study involving 50 registered antenatal cases visiting the obstetrics outpatient department, SSIMS and RC, Davangere within 18-28 weeks gestation of a singleton pregnancy with nil proteinuria upon dipstick measurement were included. Relevant history was taken. After confirming the inclusion and exclusion criteria, detailed general and physical examination including maternal height, weight, abdominal circumference, symphysio-fundal height was done. ACR was determined from random single midstream urine sample taken between 18-28 weeks of gestation collected in a sterile container of $20 \mathrm{ml}$ amount.

Estimation of urinary protein was done by immunoturbidometric microalbumin method on Dade Dimension Auto analyzer, which automatically calculates the urinary protein concentration of each urine sample. Conversion factor $(\mathrm{f})=\mathrm{mg} / \mathrm{L} \times 0.1=\mathrm{mg} / \mathrm{dL} ; \mathrm{mg} / \mathrm{L} \times$ $0.001=\mathrm{g} / \mathrm{L}$ To calculate 24 -hour urine protein excretion: $\mathrm{mg} / \mathrm{L} \times$ total volume (litres per 24 hours) $=\mathrm{mg} /$ day .

Estimation of urinary creatinine by modified Jaffe's method on Hitachi 911 Auto analyzer instrument with commercially available reagents was done in Central Lab at our institute. Cut-off value of ACR (mmol of albumin $/ \mathrm{mg}$ of creatinine) was taken as $35.5 \mathrm{mg} / \mathrm{mmol}$. All these women were followed up till delivery. At each visit their BP was measured and they were evaluated for any signs and symptoms of pre-eclampsia.

\section{Inclusion criteria}

- 18-28 weeks gestation

- Primigravida and multigravida

- $\quad$ Singleton pregnancy

- Nil proteinuria upon measurement with a dipstick

- Women over 18 years.

\section{Exclusion criteria}

- Women with hematuria, dipstick positive proteinuria

- Ongoing urinary tract infection, multiple pregnancy

- Acute renal failure

- Chronic kidney disease

- Previous bad obstetric outcome

- Chronic hypertension

- Diabetes

- Family history of hypertension and those not willing to participate. 


\section{Statistical analysis}

The data was analyzed using chi square test and Fisher's t test. A statistical package SPSS version 17.0 was used and P-value $<0.05$ is considered significant.

\section{RESULTS}

\section{Demographic characteristics}

Majority (42\%) of patients were in the age group of 25 to 29 years with $68 \%$ dwelling from rural background. 34 $(68 \%)$ were primigravidas and 16 were multipara $(32 \%)$.
Maternal age and body mass index (BMI) showed no significant difference between the groups $(\mathrm{P}>0.05, \mathrm{P}$ value being 0.53899). Gestational age, systolic and diastolic blood pressures were highly significant in preeclamptic pregnant women as compared to healthy normotensive pregnant women $(\mathrm{P}<0.001)$ (Table 1$)$.

The Mean \pm SD of ACR amongst normotensive women was $21.8 \pm 12.9$ and amongst pre-eclamptic women was $53.2 \pm 19.6$, the difference being statistically significant $(\mathrm{P}$ $=0.0008$ ) (Table 2). Of the total 50 patients; 10 patients had high ACR value, with $8(80 \%)$ developing preeclampsia and $2(20 \%)$ (Table 3$)$.

Table 1: Anthropometric data of patients.

\begin{tabular}{|lll|}
\hline Anthropometric factors & $\begin{array}{l}\text { Group A- healthy normotensive } \\
(\mathbf{N}=\mathbf{4 2}) \text { Mean } \pm \text { SD }\end{array}$ & $\begin{array}{l}\text { Group B- hypertensive women } \\
(\mathbf{N}=\mathbf{8}) \text { Mean } \pm \text { SD }\end{array}$ \\
\hline Age, years & $19.02 \pm 2.65$ & $30.2 \pm 3.24$ \\
\hline BMI, $\mathrm{kg} / \mathrm{m}^{2}$ & $22.01 \pm 1.64$ & $26.3 \pm 1.67$ \\
\hline Gestational age, weeks & $22.26 \pm 2.69$ & $26.5 \pm 1.94$ \\
\hline Systolic blood pressure, $\mathrm{mm}$ of $\mathrm{Hg}$ & $110.33 \pm 6.74$ & $160.5 \pm 17.46$ \\
\hline Diastolic blood pressure, $\mathrm{mm}$ of $\mathrm{Hg}$ & $72.33 \pm 5.47$ & $114.77 \pm 14.5$ \\
\hline
\end{tabular}

Table 2: Distribution of urinary ACR among normotensive and preeclamptic women.

\begin{tabular}{|llc|}
\hline Urinary ACR & Normotensive $(\mathbf{N}=\mathbf{4 2})$ & Pre-eclamptic $(\mathbf{N}=\mathbf{8})$ \\
\hline Mean \pm SD & $21.8 \pm 12.9$ & $53.2 \pm 19.6$ \\
\hline Range & $9.7-30$ & $13.4-79.0$ \\
\hline Median & 19.60 & 53.2 \\
\hline Mean difference & 32.69 & \\
\hline P-value & $0.0008^{*}$ & \\
\hline
\end{tabular}

Table 3: Distribution of women according to test positivity.

\begin{tabular}{|llll|}
\hline Test used in study & Test positive $(\mathbf{N})$ & Test negative $(\mathbf{N})$ & Total (N) \\
\hline ACR $(\mathrm{C} 35.5 \mathrm{mg} / \mathrm{mmol})$ & $10(20 \%)$ & $40(80 \%)$ & $50(100 \%)$ \\
\hline
\end{tabular}

Table 4: Association of ACR with pre-eclampsia.

\begin{tabular}{|llll|}
\hline ACR & Normotensive $(\mathbf{N})$ & Pre-eclampsia $(\mathbf{N})$ & Total $(\mathbf{N})$ \\
\hline Test positive & $2(20 \%)$ & $8(80 \%)$ & $10(20 \%)$ \\
\hline Test negative & 40 & 0 & $40(80 \%)$ \\
\hline Total & $\mathbf{4 2}(\mathbf{8 4 \% )}$ & $\mathbf{8}(\mathbf{1 6 \%})$ & $\mathbf{5 0}(\mathbf{1 0 0 \%})$ \\
\hline
\end{tabular}

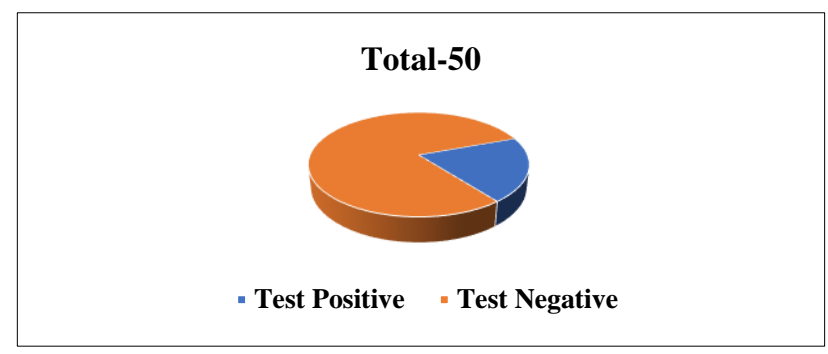

Figure 1: Distribution of ACR positive and negative patients.
Of the total 50 patients; 10 patients had high ACR value, with $8(80 \%)$ developing pre-eclampsia and $2(20 \%)$ remaining normotensive (Table 4).

Out of total 50 patients; 40 patients were test negative and remaining 10 patients were test positive (Figure 1).

The ACR had a sensitivity of $80 \%$, specificity $97.56 \%$, positive predictive value of $88.89 \%$. The diagnostic accuracy of the test was $94.12 \%$ (Figure 2). 


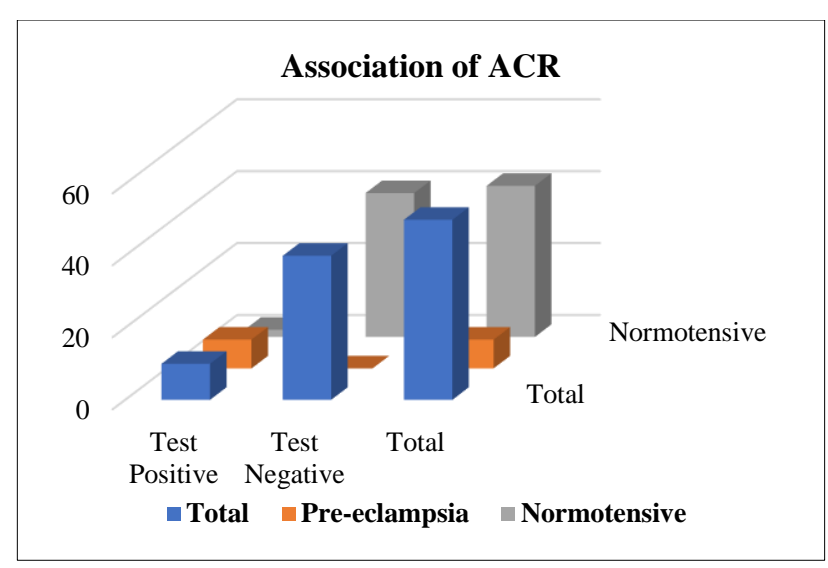

Figure 2: Association of ACR with pre-eclampsia.

\section{DISCUSSION}

Proteinuria remains an important diagnostic criterion that defines the widespread endothelial leak, characteristic of pre-eclampsia. Proteinuria increases through the trimesters, during normal pregnancy from $0.15 \mathrm{~g} / \mathrm{d}$ outside pregnancy to $0.3 \mathrm{~g} / \mathrm{d}$ during pregnancy. This is attributable to the increase in renal plasma flow and glomerular filtration rate, as well as changes in protein handling in the nephron, these changes resolve after pregnancy.

Earlier days dipstick was the common bedside test for urine albumin in pregnancy. A study of 198 hypertensive women by Waugh et al, women with significant proteinuria had very high false negative rate of $65 \%$ in dipstick analysis with $<1+$ proteinuria. $^{12}$

Mercer et al, in a study reported $66 \%$ false negative reports in dipstick analysis in hypertensive women with significant proteinuria $\geq 300 \mathrm{mg} / 24$ hours. In same study false positive rates of $26 \%$ at $1+$ proteinuria with dipstick had also been reported. ${ }^{8}$

The main finding in our study was that of the total 50 patients; 10 patients had high ACR value, with $8(80 \%)$ developing pre-eclampsia and 2 (20\%) remaining normotensive. The Mean \pm SD of ACR amongst normotensive women was $21.8 \pm 12.9$ and amongst preeclamptic women was $53.2 \pm 19.6$, the difference being statistically significant $(\mathrm{P}=0.0008)$.

A meta-analysis by Morris et al. which included thirteen studies showed that on average, the optimum threshold was between 0.30 and 0.35 and concluded that the maternal "spot urine" estimate of protein to creatinine ratio shows promising diagnostic value for significant proteinuria in suspected pre-eclampsia. ${ }^{13}$

In our study, the cut-off value of ACR (mmol of albumin/mg of creatinine) was taken as $35.5 \mathrm{mg} / \mathrm{mmol}$. Cade et al, concluded that the urine protein to creatinine ratio is highly accurate in predicting significant proteinuria in women with pre-eclampsia using the recommended cut-off of $30 \mathrm{mg} / \mathrm{mmol}^{14}$

Then the consideration of 24-hour urinary protein excretion for estimation of proteinuria was done. It was time consuming and not feasible in pregnancy. Eigbefoh et al, showed that there is a strong correlation between random urinary protein-to-creatinine ratio and quantitation of 24-hour proteinuria with sensitivity of $92 \%$ specificity for the protein/creatinine ratio was $86 \%$. $^{15-17}$

Sami Jan et al, concluded that spot urine protein to creatinine ratio is an accurate, reliable and steady fast, time saving test which can be used as an alternative method for evaluation of proteinuria in pregnancy induced hypertension and it can substitute 24 hours urinary protein excretion estimation in clinical practice. ${ }^{18}$

A cross sectional study of 920 hospitalized patients with suspicion of preeclampsia, Mishra et al, concluded that spot UPCR can be used as a reasonable alternative to 24 hours urine protein estimation with a sensitivity and specificity of $98.1 \%$ and $98.6 \%$ positive predictive value and negative predictive value $97.4 \%$ and $99.2 \% .{ }^{19}$

A single spot urinary ACR was used in this study because it is more feasible in clinical practice as a screening test and 24 hours collection would have been more timeconsuming and cumbersome. The incidence of preeclampsia in our study group is $20 \%$ which is significantly higher to the incidence of $4-18 \%$ in developing countries. Authors found that spot urinary ACR at 18-28 weeks of gestation was significantly higher in women who subsequently developed pre-eclampsia with mean value of $532 \pm 196.3 \mathrm{mg} / \mathrm{gm}$. The sensitivity of ACR at a cut-off value of $>=35.5 \mathrm{mg} / \mathrm{mmol}$ was $80 \%$ which is comparable to studies done by Baweja et al, $(83.3 \%)$ and specificity of $97.56 \%$, PPV of $88.89 \%$ and a $91.5 \%$ NPV for later development of pre-eclampsia. Diagnostic accuracy of the test was $94.12 \% .^{20}$

These statistical analysis shows that spot urinary ACR has a good predictive role as screening test for preeclampsia in early pregnancy. Therefore, spot urinary albumin:creatinine ratio (ACR) has been advocated as an alternative in various studies.

It is uncertain whether pharmacological interventions starting from the first trimester rather than the second trimester would prove to be more effective, but before this could be investigated, it is essential to develop a method of effective and early identification of the highrisk group.

\section{CONCLUSION}

Spot urine protein creatinine ratio is a quick, reliable, acceptable and cost-effective alternative as a predictor 
test for the detection of significant proteinuria among asymptomatic antenatal women.

\section{Funding: No funding sources}

Conflict of interest: None declared

Ethical approval: The study was approved by the Institutional Ethics Committee

\section{REFERENCES}

1. Montan S, Sjoberg N, Svenningsen N. Hypertension in pregnancy-fetal and infant outcome: a cohort study. Hypertens Preg. 1987;6:337-48.

2. Khan K, Wojdyla D, Say L, Gulmezoglu A, Van Look PF. WHO analysis of causes of maternal death: a systematic review. Lancet. 2006;367:1066-74.

3. World Health Organization. WHO international collaborative study of hypertensive disorders of pregnancy: geographic variation in the incidence of hypertension in pregnancy. Am J Obstet Gynecol. 1988;158:80-3.

4. Sogani S, Varma V, Sarkar P. Significance of urine albumin/creatinine ratio (UACR) and uric acid in women with preeclampsia and its comparison with healthy normotensive pregnant women in their third trimester. Acta Medica Lituanica. 2014;21(1):9-15.

5. Dong X, Gou W, Li C, Wu M, Han Z, Li X et al. Proteinuria in preeclampsia: not essential to diagnosis but related to disease severity and fetal outcomes. Preg Hypertens. 2017;8:60-4.

6. Kim M, Kim Y, Jung E, Jang H, Byun J, Jeong D et al. Is massive proteinuria associated with maternal and fetal morbidities in preeclampsia? Obstet Gynecol Sci. 2017;60(3):260-5.

7. Meyer NL, Mercer BM, Friedman SA, Sibai BM. Urinary dipstick protein: a poor predictor of absent or severe proteinuria. Am J Obst Gynecol. 1994;170:13741.

8. Côté AM, Firoz T, Mattman A, Lam EM, von Dadelszen P, Magee LA. The 24-hour urine collection: gold standard or historical practice? Am J Obst Gynecol. 2008;199:e1-6.

9. Vassalotti JA, Stevens LA, Levey AS. Testing for chronic kidney disease: a position statement from the National Kidney Foundation. Am J Kidney Dis. 2007;50:169-80.

10. Brown MA, Lindheimer MN, De Swiet M, Van Assche A, Moutquin JM. The classification and diagnosis of the hypertensive disorders of pregnancy: statement from the International Society for the Study of Hypertension in Pregnancy (ISSHP). Hypertens Preg. 2001;20:9-14.
11. Waugh J, Hooper R, Lamb E, Robson S, Shennan A, Milne F, et al. Spot protein-creatinine ratio and spot albumin-creatinine ratio in the assessment of preeclampsia: a diagnostic accuracy study with decision-analytic model-based economic evaluation and acceptability analysis. Health technology assessment (Winchester, England). 2017;21(61):1.

12. Morris R, Riley R, Doug M, Deeks J, Kilby M. Diagnostic accuracy of spot urinary protein and albumin to creatinine ratios for detection of significant proteinuria or adverse pregnancy outcome in patients with suspected preeclampsia. Obstet Gynecol Surv. 2012;67(11):681-2.

13. Cade TJ, Gilbert SA, Polyakov A, Hotchin A. The accuracy of spot urinary protein-to creatinine ratio in confirming proteinuria in pre-eclampsia. Aust N Z J Obstet Gynaecol. 2012;52(2):179-82.

14. Lokhande MC, Jadhao AN. Role of random urinary protein to creatinine ratio in mild preeclampsia. NJMR. 2016;6:4.

15. Pariyaeksut $\mathrm{P}$, Lertbunnaphong $\mathrm{T}$, Leetheeragul J, Boriboonhirunsarn D. A correlation between firstvoid morning urinary protein to creatinine ratio (UPCR) and 24 hours urinary protein in pregnancy with suspected preeclampsia. Thai J Obstet Gynaecol. 2014;22:173-80.

16. Demirci O, Kumru P, Arınkan A, Ardıç C, Arisoy R, Tozkır E, et al. Spot protein/creatinine ratio in preeclampsia as an alternative for 24-hour urine protein. Balkan Med J. 2015;32:51-5.

17. Jan S, Javaid C, Firdous N. Diagnostic accuracy of spot urinary protein/creatinine ratio for proteinurea in pregnancy induced hypertension. Int $\mathbf{J}$ Reprod Contracept Obstet Gynecol. 2017;6(5):2083-9.

18. Mishra VV, Preeti G, Roy P, Rohina A. Evaluation of spot urinary albumin -creatinine ratio as screening tool in prediction of pre-eclampsia in early pregnancy. J Obstet Gynaecol India. 2017;67(6):4058.

19. Baweja S, Kent A, Masterson R, Robert S, McMohon LP. Prediction of preeclampsia in early pregnancy by estimating the spot urinary albumin:creatinine ratio using high performance liquid chromatography. BJOG. 2011;118:1136-32.

Cite this article as: Rajeshwari G, Dongare AG, Patil GL, Pujar T. Evaluation of spot urinary albumin - creatinine ratio as a screening tool in the prediction of pre-eclampsia in early pregnancy: a pilot study. Int J Reprod Contracept Obstet Gynecol 2020;9:575-9. 